\title{
DETERMINATION OF SOURCE ROCK POTENTIAL USING TOC MODEL LOG, NGIMBANG FORMATION, NORTH EAST JAVA BASIN
}

\author{
Yosar Fatahillah ${ }^{1)}$, Widya Utama ${ }^{1)}$, Anik Hilyah ${ }^{1)}$, Kukuh Suprayogi ${ }^{2)}$ \\ ${ }^{1)}$ Department of Geophysics Engineering, ITS, ${ }^{2)}$ Pertamina Upstream Technology Center \\ e-mail: yosar12@mhs.geofisika.its.ac.id
}

\begin{abstract}
Ngimbang Formation is known as one major source of hydrocarbon supply in the North Eastern Java Basin. Aged Mid-Eocene, Ngimbang is dominated by sedimentary clastic rocks mostly shale, sandstone, including thick layers of limestone (Mostly in Lower Ngimbang), with thin layers of coal. Although, laboratory analyses show the Ngimbang Formation to be a relatively rich source-rocks, such data are typically too limited to regionally quantify the distribution of organic matter. To adequately sample the formation both horizontally and vertically on a basin-wide scale, large number of costly and time consuming laboratory analyses would be required. Such analyses are prone to errors from a number of sources, and core data are frequently not available at key locations. In this paper, the authors established four TOC (Total Organic Carbon Content) logging calculation models; Passey (1990), Schmoker-Hester (1983), Meyer-Nederloff (1984), and Decker/ Density Cross plot Model (1993) by considering the geology of Ngimbang in North Eastern Java Basin. Three wells data along with its available core data was used to determine the most suitable model to be applied in the formation, as well as to compare the accuracy of these TOC model values. Cutoff value of 1.5 in deviation was applied to quantify the minimum amount of acceptable error. This cutoff value was applied based on the standardized TOC model to core deviation used for qualitative interpretation column to scaling ratio. Since, Meyer-Nederloff model couldn't be used to determine the TOC value as other three models, this model was only used as standard comparison model.
\end{abstract}

Keywords: TOC; vitrinite reflectance; passey; ngimbang; well-log

\section{INTRODUCTION}

Ngimbang is one of four proven major supplier of organic rich source rocks in the petroleum system of the North Eastern Java (NEJ) Basin (Saultan Panjaitan, 2010). Known as the oldest formation of sedimentary deposits in the basin. Ngimbang lays on top of the basement of the NEJ basin. Aged Mid-Eocene, Ngimbang is dominated by sedimentary clastic rocks mostly shale, sandstone, including thick layers of limestone (Mostly in Lower Ngimbang), with thin layers of coal (Mudjiono and Pireno, 2001).

North East Java Basin was formed through northward plate collision between Austro-Indian plate and Sunda plate. Characterized with low anomaly in collision area and high anomaly in south Java mountain range. The meeting of ocean crust of India and continental crust from sunda plate forms islandic arch system (Satyana and Purwaningsih, 2003).
One of the biggest concern in determining the TOC valueis the cost of cutting or coring analysis. Besides, the relatively high possibility of errors from many external factors, theresult of laboratory analyses are sometimes limited and not available at key locations/ depth (Hester and Schmoker, 1987). Classification of TOC Quality and Formation Maturity can bee seen in Table 1 . and Table 2.

In this study, four wells was used to observe the characteristics of distribution of TOC in the Ngimbang Formation. These wells are $\mathrm{SH}-1, \mathrm{SH}-2$, $\mathrm{SH}-3$, and AFA-1. However well AFA-1 is the only well where no TOC core data is available. Therefore, this well was used as comparison well to prove whether the TOC in the well based on determined applicable model from well SH-1, SH-2, and $\mathrm{SH}-3$ is considered to be having proper TOC value.

The identification of the total organic content of the source rocks in the subsurface, its type and levels of maturity are a very important motive in 
the field of petroleum exploration. So, this work can be considered as a trial to provide information about hydrocarbon source rock potential of the fomation, using well log data (Schmoker, 1981).

A method of determining organic content from formation physical properties logs (well log data) which was proven to be accurate in predicting real TOC from laboratory analysis in the studeis of various basins around the world, offers a practical alternative to laboratory analysis of core or cuttings. The well log data derived method has several advantages over laboratory analyses including but not limited to (Abdel-Rahman, 2013):

- The well-log data provides continuous measurement of the formation, reducing statistical unvertainities of limited and sometimes random picked spot sampling;

- Well log data are more common and more readily available than core cuttings;

- Working with well logs data is simpler and less costly than laboratory procedues.

Table 1. Classification of Organic Qualit.

\begin{tabular}{c|ccc} 
Quality & TOC & S1 & S2 \\
\hline Poor & $0-0.5$ & $0-0.5$ & $0-2.5$ \\
Fair & $0.5-1$ & $0.5-1$ & $2.5-5$ \\
Good & $1-2$ & $1-2$ & $5-10$ \\
Very Good & $>2$ & $>2$ & $>10$
\end{tabular}

Table 2. Maturity Level.

\begin{tabular}{c|ccc} 
Maturation & Ro & LOM & Tmax \\
\hline Immature & $<0.6$ & $<9$ & $<420$ \\
$\begin{array}{c}\text { Mature } \\
\text { Post }\end{array}$ & $0.6-1.4$ & $9-11.5$ & $435-445$ \\
Mature & $>1.4$ & $>11.5$ & $>470$
\end{tabular}

\section{Rock-Eval Pyrolysis}

Rock-Eval pyrolysis gives information on the quantity, type and thermal maturity of the organic matter. Pyrolysis is a widely used degradation technique that allows breaking a complex subsidence into fragments by heating it under inert atmosphere (see Table 1 and Table 2). Rock-Eval data are expressed as $\mathrm{mg} / \mathrm{g}$ of rock and include four basic parameters (Peter and Cassa, 1994)

- S1 represents the quantity of free hydrocarbons present in the rock and is roughly analogous to the solvent extractable portion of the organic matter;

- S2 represents the quantity of hydrocarbons released by the kerogen in the sample during pyrolysis;

- T-max is the temperature at which the maximum rate of generation (of the S2 peak) occurs and can be used as an estimate of thermal maturity.

\section{METHOD}

The methods used in this paper is based upon proven models that has previously been tested in various basins. However the main objective of this paper is to review the assumptions and methodology of the approach and establishes the validity and limitations and inspect further observations of possible improvement of the method, by comparing log derived data to laboratory analyses result.

In this paper the authors established 5 TOC log Model:

- Schmoker-Hester Model (1983)

- Meyer-Nederloff Model (1984)

- Passey/ DlogR Method (1990)

- Decker Model (1992)

- Improved Decker Model (2016)

Since TOC core data in the wells are mostly taken on random sampling wihout certain interval picks, this paper uses deviaton method where each TOC value taken from log model is summed with the core TOC value taken from laboratory analyses. High deviation value describes poor agreement between TOC model Log and TOC result of laboratory analyses. Thus, will further be considered as unsuitable to be applied in the formation or just on certain depth intervals area. 


\section{Schmoker-Hester Model (1983)}

Based upon four major components. The content of pyrite in the formation, interstitial pore fluid of the formation, rock matrix, and organic matter (Sharawy and Gaafar, 2012). These four components was fitted to the to the Bakken Formation. Thus follows the empirical state of the Bakken geological background. However, the final formula given by Schmoker-Hester (1983) was one of the simplest TOC calculation form.

$$
\operatorname{TOC}(w t . \%)=\left(\frac{154.497}{\rho}\right)-57.261
$$

Where $\rho$ is the formation density taken from density log. TOC calculated using this method shows poor qualitative result. Therefore, enermous deviation value on quantitative analysis was found. Average value of deviation on the experiment of well $\mathrm{SH}-1$ is 1.77 , Deviation on $\mathrm{SH}-2$ is 3.38 , and $\mathrm{SH}-$ 3 is 3.39

\section{Decker Model (1993)}

Based upon the theoretical basis that the organic matter density $(1.03-1.10 \mathrm{~g} / \mathrm{cm} 3)$ in shale is significantly lower that of surrounding rock matrix (the density of clay skeleton is $2.30-3.10 \mathrm{~g} / \mathrm{cm} 3$ ), resulting in lower well logging density of highquality source rocks (Decker, Hill, and Wicks, 1993). For organic-rich, low-porosity and low permeability shale, formation rock density varies with the variation of organic matter abundance.

There is a certain relationship between TOC and total formation bulk density of Ngimbang formation source rocks. Therefore, it is possible to work TOC through this relationship, because the formation bulk density can be accurately measured by conventional well logging (Renchun et al., 2015). Therefore, the formula for calculating TOC by density well logging is written as:

$$
\text { TOC }(w t . \%)=A+B \rho
$$

Where $\rho$ is well logging density, $\mathrm{g} / \mathrm{cm} 3 ; \mathrm{a}$ and $\mathrm{b}$ are Shale regional empirical factors.
Based on the experiment data of 12 core samples in Well SH-1 taken from shale stone (abnormal data points should be eliminated in the establishment of interpretation model), and leastsquare fitting, the empirical factors of Shale of Upper Ngimbang Clastics calculated are:

$$
a=-2.970, b=8.034, c c=0.867
$$

Only applicable in Shale formation, with relatively same Maturity - Ro (Vitrinite Reflectance )or LOM indicator (Figure 1).

This relatively good corelation coefficient ( $c c>0.8$ ), is resulted from minimum range variation in the TOC value with respect to the change (increasement, or decreasing) density value. Therefore, formed linear line that have rather poor distribution point throughout the linear regressioned line.

Regression process is also applied to gain correlation between the Limestone and the formation density. This relation is written in mathematical notation as written bellow.

$$
c=5.107, d=-12.3262, c c=0.4367
$$

where $\mathrm{c}$ is gradient constant, and $\mathrm{d}$ is the intercept constant taken from limestone of Ngimbang formation. Applicable in Limestone formation with relatively same maturity level. Thus, classification between upper and lower Ngimbang should be conducted.

\section{Meyer \& Nederloff Model (1984)}

Uses discrimination of Source Rocks from Nonsource Rocks Meyer and Nederlof (Meyer and Nederlof, 1984) developed an approach to recognize the source rocks from non source rocks using well log readings, that based on the resistivity log values cross plotted with either the sonic or density log values. The resistivity values used in these plots must be standardized to $75^{\circ} \mathrm{F}$ using Arps formula:

$$
R 75^{\circ}=R(T-7) / 82
$$


Where $\mathrm{R}$ is the resistivity of rocks corrected to a75 degree standard temperature of ${ }^{\circ} \mathrm{F}\left(24^{\circ} \mathrm{C}\right)$ and $\mathrm{T}$ is formation temperature at the concerned depth.

The formation temperature is derived from a gradient derived from the bottom hole temperature of the various logging runs Two linear equations, postulated by Meyer and Nederlof. For the discriminant score (D), are used on the basis of log combination R- $\rho$ and R- $\Delta$ tis the 75 bulk density in $\mathrm{g} / \mathrm{cm}$ and fit is the interval transit time in $3 \mu$ $\mathrm{sec} / \mathrm{ft}$ in the form:

$$
\begin{gathered}
D=-6.906+3.186 \log (\Delta t) \\
+0.487 \log \left(R 75^{\circ}\right) \\
\begin{aligned}
& D=2.278-7.324 \log (\rho) \\
&+ 0.387 \log \left(R 75^{\circ}\right)
\end{aligned}
\end{gathered}
$$

If $D$ is positive, the rock is a probable source rock; if $D$ is negative, the rock is probable barren.

\section{Passey Model (1990)}

Passey developed a technique used for both carbonates and clastics using sonic-resistivity overlay. They also introduced the term " $\Delta \log R$ " which is linearly related to TOC and is a function of maturity. In this technique, sonic travel time " $\Delta \mathrm{t}$ " and true formation resistivity " $\mathrm{Rt}$ " are scaled such as a ratio of $164 \mu \mathrm{s} / \mathrm{m}$ to one resistivity cycle. The separation between two curves ( $\Delta \mathrm{t}$ to left and Rt to right) defined $\Delta \log R$ that can be calculated from the following equation:

$$
\begin{gathered}
\Delta \log R= \\
\log \text { RRbaseline }+0.02 \Delta t-\Delta \text { tbaseline }
\end{gathered}
$$

In this paper we also utilize the density log as an alternative solution in finding TOC value, using the following equation:

$$
\begin{gathered}
\Delta \log \text { Rden }=\log \left(\frac{R}{\text { Rbaseline }}\right)+2.5(\rho b- \\
\text { pbaseline })
\end{gathered}
$$

Then, the TOC is calculated using the following relation:

$$
\text { TOC (wt. \%) } \Delta \log R * 10^{(2.297-0.1688 L O M)}
$$

The value of LOM (Level of Metamorphism) needed to use Passey Model was determined by using cross plot between DlogR and TOC from core data. Using the cross plot we determine the value of LOM in the range of 11 to 12 . However, Passey method is only limited to LOM value of 10.5 . Therefore, we used 10.5 instead of 11.5. However, we expect erroneous result from this calculation. Applicable in rocks with $\Delta t$ ranges from 262 to 460 $\mu \mathrm{s} / \mathrm{m}$, And LOM ranges from 6-10.5, with Ro- 0.5 to 0.9 (Renchun et al. 2015).

\section{RESULT AND DISCUSSION}

From the above mentioned method, the TOC calculation model for the Ngimbang Formation was defined. The result describes the lack of accuracy of Schmoker-Hester Model. In contrast, the Passey and Decker Model gives satisfactory result with very small amount of deviation from core data TOC.

Decker-Shale model is applicable in the shale zone of the Ngimbang Formation. Since, only shale data are taken into account during least-square processing. There's no proven correlation between the formation density to the TOC of Limestone by using this method. Thus, Low deviation in Limestone are considered as incidental.

Since, Decker Shale Model is only applied to the Shale interval, similar approach with Decker model is needed to be applied in the limestone intervals. The result shows this method is also applicable, but the shall be carefully maintained, as erroneous result is expected. Most of them occurs on the Lower Ngimbang Limestone. We concluded that this was a result of difference in geologic background, that was indicated through available Ro data. Unlike the case of Upper Ngimbang Shale (Clastics) which has minimum difference in maturity level, Lower Ngimbang has various maturity level rangging from Immature (Ro<0.65), 
Mature (Ro>0.65), and Post Mature (Ro>1.4) with no liniear correlation to depth of Interval.

DlogR (Passey) Model both Sonic and Density derived Model shows both promising quantitative result. However, as Passey has pointed out that the method is only applicable when the LOM of the formation ranges from 6.0 to 10.5 (Peter and Cassa, 1994). The determined LOM value of 11.5 is considered to be "non Passey". Morover, This model is valid only in $\Delta$ t (Sonic Log) ranging from 262 to $460 \mu \mathrm{s} / \mathrm{m}$. Error in TOC calculation can be expected at extreme low or high $\Delta t$ due to the proposed scale is not valid at this situation (Peter and Cassa, 1994). Combination of both LOM (above the range) and Sonic Log (below) range in the formation often gives negative separation, and gives erroneous TOC calculation result. Thus this method shall be used more prudently.

Since, Schmoker-Hester Model is based upon Shale Source Rocks experiment, there's no correlation between the model towards the application on Limestone. The equation is only usable in shale zone with high pyrite component, and specific ration of organic matter to organic carbon relatively around range of 1.33 with density of organic matter not far from $1.01 \mathrm{~g} / \mathrm{cm} 3$. Low pyrite component and undetermined OM (organic matter) to (OC) Organic Carbon ratio. Unfeasible both in Shale and Limestone of Ngimbang Formation. Good quantitative result in Limestone are only considered to be incidental. Application of this method shall be recalibrated mostly from the Pyrite component, and Organic Matter-Organic Carbon Ratio.

\section{Conclusions}

Several conclusions have been taken. Based on the application of each model on the Ngimbang Formation, we concluded that:

- Decker-Shale method is applicable in the shale zone of the Ngimbang Formation. Since, only shale data are taken into account during leastsquare processing.There's no proven correlation between the formation density to the TOC of Limestone by using this method.
Thus, Low deviation in Limestone are considered as incidental.

- Decker-Limestone method is applicable, but the usage of this method shall be carefully maintained, as erroneous result is expected.

- Since, the qualitative and quantitave analysis has shown promising result, Passey Density method should be used prudently. As most of the Ngimbang formation intervals are considered to be "non-Passey" when the LOM is beyond the range of 6-10.5.

- Passey-Sonic Method- Combination of both LOM (above the range) and Sonic Log (below) range in the formation often gives negative separation, and thus gives erroneous TOC calculation result.

- Schmoker-Hester Model in unfeasible both in Shale and Limestone of Ngimbang Formation. Good quantitative result in Limestone are only considered to be incidental. Application of this method shall be recalibrated mostly from the Pyrite component, and Organic Matter-Orcanic Carbon Ratio.

\section{REFERENCES}

Ali Younis Ahmed Abdel-Rahman., 2013. Source Rock Evaluation and Maturity Levels of the Rudeis Formation, Northern Gulf of Suez, Egypt, Using Well Log Analysis and Rock-Eval Pyrolysis. Giza, Egypt: Department of Geophysical Science, National Research Center.

Decker AD, Hill DG, Wicks DE. Log-based Gas Content and Resource Estimates for The Antrim Shale, Michigan Basin. In: Paper MS-25910 presented at the Low Permeability Reservoirs Symposium. New York: SPE; 1993. 26e28 April 1993. Denver, Colorado, USA.

Hester. T \& Schmoker J.W., 1987. Determination of Organic Content From Formation-Density Logs. Devonian-Mississippian Woodford Shale, Anadarko Basin, Oklahoma. Denver Colorado: Department of Internal U.S Geological Survey.

Huang Renchun et al., 2015. Selection of Logging-based TOC Calculation Methods for Shale Reservoirs: A Case Study of the Jiaoshiba Shale Gas Field in the Sichuan Basin. Research Institute of Sinopec Exploration Southern Company, Chengdu, Sichuan 610041. 
Meyer, B.L., Nederlof, M.H., 1984. Identification of Source Rocks on Wireline Logs by Density/Resistivity and Sonic Transit Time/Resistivity Cross Plots. AAPG Bulletin. V. 68, p.121- 129 .

Mohamed S. El Sharawy, Gamal R. Gaafar, 2012. Application of well log analysis for source rock evaluation in the Duwi Formation, Southern Gulf of Suez, Egypt. Journal of Applied Geophysics 80 (2012) 129-143.

Mudjiono dan Pireno, 2001. Exploration of The North Madura Platform, Offshore East Java, Indonesia, Proceedings Indonesia Petroleum Association 28th Annual Convention and Exhibition, Jakarta.

Passey, Q.R., Moretti, F.U., Stroud, J.D., 1990. A Practical Modal for Organic Richness from Porosity and Resistivity Logs. AAPG Bulletin. V. 74, p. 17771794. logs II: Geol. Soc. London, Spec. Publ., 65, pp. 369- 376.

Peter, K.E and Cassa, M.R, 1994. Applied Source Rock Geochemistry. AAPG Memoir 60, The Petroleum System From Source to Trap, AAPG. Tulsa, Oklahoma.

Satyana A.H and Purwaningsih, M.E.M., 2003. Geochemistry of the East Java Basin: New Observations on Oil Grouping, Genetic Gas Types and Trends of Hydrocarbon Habitats, in Proceedings IPA 29th Convention and Exhibition, Jakarta.

Saultan Panjaitan, 2010. Prospek Migas pada Cekungan Jawa Timur dengan Pengamatan Metode Gaya Berat. Bandung: Buletin Sumber Daya Geologi. Volume 5 Nomor 3-2010.

Schmoker JW., 1981. Determination of Organic-matter Content of Appalachian Devonian Shales from Gamma-ray Logs. AAPG Bull. 65(7):1285e98.

\section{NOMENCLATURE}

- $\Delta \mathrm{t}$ the sonic log value, $\mu \mathrm{s} / \mathrm{m}$

- $\rho$ the density, gm/cm3

- Rbaseline, Resistivity on the baselined intervals.

- LOM the level of maturity, 6- 7 for onset of maturity for oil-prone kerogen and 12 corresponds to the onset of over maturity for oil-prone kerogen.

- $\quad \mathbf{R} 75^{\circ}$ the log resistivity corrected to 75 of.
- S1 represents the quantity of free hydrocarbons present in the rock and is roughly analogous to the solvent extractable portion of the organic matter;

- S2 represents the quantity of hydrocarbons released by the kerogen in the sample during pyrolysis;

- T-max is the temperature at which the maximum rate of generation (of the S2 peak) occurs and can be used as an estimate of thermal maturity. 